Article

\title{
Soft Presentation of Hard News? A Content Analysis of Political Facebook Posts
}

\author{
Miriam Steiner \\ Department of Communication, Johannes Gutenberg University, 55099 Mainz, Germany; \\ E-Mail: miriam.steiner@uni-mainz.de
}

Submitted: 14 April 2020 | Accepted: 5 July 2020 | Published: 24 August 2020

\begin{abstract}
The current media environment is primarily characterised by a large amount of information and, in contrast, rather fragmented audience attention. This is especially true for social media, particularly Facebook, which have become important news sources for many people. Journalists cannot help but publish content on Facebook if they want to reach the part of their audience that mainly-or even only-consumes news there. On Facebook, journalists are at the mercy of the algorithm that determines the visibility of their content. Because user engagement is a crucial factor in the algorithm, concerns have been raised that journalists are abandoning their normative quality standards to make the news as attractive as possible to the audience-at the expense of media performance. A softened presentation of the news, particularly in Facebook posts, may help achieve this aim, but research on this subject is lacking. The present study analyses this practice of softening the news in four German media outlets' (BILD, FAZ, Der Spiegel, Tagesschau) political Facebook posts. The results show that the overall level of news softening is low to medium. Furthermore, comparing them to website teasers reveals that news softening is only slightly higher on Facebook (mainly BILD and Der Spiegel), and that there are no converging trends between quality or public service media and tabloid media. Exaggerated fears about news softening are therefore unnecessary. Continued analysis of news softening, as well as ongoing adaption of the concept according to dynamic developments, is nevertheless important.
\end{abstract}

\section{Keywords}

Facebook; Germany; journalism; political news; quantitative content analysis; social media logic; soft news

\section{Issue}

This article is part of the issue "Media Performance in Times of Media Change" edited by Melanie Magin (Norwegian University of Science and Technology, Norway) and Birgit Stark (Johannes Gutenberg University Mainz, Germany).

(C) 2020 by the author; licensee Cogitatio (Lisbon, Portugal). This article is licensed under a Creative Commons Attribution 4.0 International License (CC BY).

\section{Introduction}

The current media environment has made it increasingly difficult for journalists to attract attention. This is particularly true for social media, which have become important news sources for many people in recent years (Newman, Fletcher, Kalogeropoulos, \& Nielsen, 2019). Although Facebook's importance has somewhat decreased most recently and the younger audience is increasingly turning to Instagram, Facebook remains by far the most important social media platform for news (Newman et al., 2019). Consequently, journalists must publish content on this platform (e.g., Lischka, 2018) to reach their entire audience. However, Facebook cre- ates a dilemma: On the one hand, journalists want to inform people as fully as possible; on the other hand, to achieve this goal, their content must be visible, and its visibility is determined by Facebook's algorithm. Users' content engagement, such as the number of reactions, shares, and comments, is particularly important in this respect (Bucher, 2012; DeVito, 2017). The algorithm in connection with user engagement thus determines which principles are important to achieve high visibility. Journalists may therefore adapt to these principles that shape the so-called social media logic (van Dijck \& Poell, 2013), that is, alter their presentation of the news to attract attention and increase engagement with the content. 
A softened presentation of the news (e.g., using emotional language to arouse emotions) may be a way to achieve this aim (Lischka, 2018). Although some studies have pointed to positive effects, particularly in the context of television (e.g., Grabe, Lang, \& Zhao, 2003), news softening is often associated with lower standards of media performance (Esser, 1999). Researchers particularly criticize the tendency of news softening to emphasise more dramatic but unimportant aspects of a news story at the expense of core information, which will lead to an insufficiently informed citizenry (e.g., Graber, 1994). News softening is therefore seen rather critically, also in the context of social media (Steiner, 2016).

Despite these concerns, research on news softening on social media is widely lacking so far. Few studies have investigated news softening on Facebook: 1) Lischka and Werning (2017) compared newspapers' selection of hard and soft news between their Facebook posts and the print editions; 2) Steiner (2016) compared the softened presentation (colloquial language, personalisation, narration, emotionalisation) of political news on television and on Facebook, including the articles linked on Facebook rather than only the posts themselves; and 3) Welbers and Opgenhaffen (2019) analysed news softening within newspapers' Facebook posts but restricted their analysis to indicators of subjective language (subjective adjectives, emoticons). The present study, a quantitative content analysis, overcomes this research gap. It derives the most important criteria of news softening from the social media logic and analyses them in the political Facebook posts of four German media outlets: BILD, Tagesschau, Der Spiegel, and Frankfurter Allgemeine Zeitung ( $F A Z$ ). Additionally, it compares individual media outlets' Facebook posts with their website teasers. In this way, the study also determines whether news softening is considerably stronger in Facebook posts and can thus be seen as a means of adapting to the social media logic.

The article begins by examining the conditions for journalism online and on social media and describes the concept of news softening as a means to cope with the shifting conditions. The article then presents the methods and the results sections and closes with a conclusion and outlook on future research.

\section{Conceptual Framework}

\subsection{User Attention in the Online and Social Media Environment}

The rise of tabloids and commercial television has long been regarded as the main driver of news softening because of the economic pressure that these media types place on news journalism. However, the growing importance of the Internet and the digitalisation of news journalism are also key factors that intensify news items' struggle for attention and may therefore result in news softening (Magin, 2019a).
From the time journalists started to provide content on their news brands' websites, they have had to fight to attract attention to finance their work. Because most people, particularly Germans, are not willing to pay for online news (Newman et al., 2019), journalists depend on high click rates to increase their advertising revenues. Therefore, they evermore use real-time audience metrics (Cherubini \& Nielsen, 2016; Tandoc, 2015; Vu, 2014) to observe how minor changes to their websites directly influence clicks. As a consequence, journalists do not only place news teasers more prominently $(\mathrm{Vu}, 2014)$ to increase the visibility of high-potential articles but may also change headlines (Cherubini \& Nielsen, 2016). Softening the presentation of website teasers may thus help to adjust to news consumers' interests.

On Facebook, journalists do not only lack audience metrics and the possibility to strategically alter the placement of news items, but also advertising revenues flow primarily to the social media platform (Bell \& Taylor, 2017). In addition, journalists' content competes with many other types of content on Facebook's marketplace of attention, with the algorithm deciding which items have greater visibility. Although the algorithm changes continuously, users' interaction with an item is the essential factor that determines how visible the item is in the newsfeeds of many others (Bucher, 2012; DeVito, 2017). This situation intensifies the need for journalists to focus on users' interests to ensure their content is as visible as possible. They may therefore face trade-offs between adhering to their news paradigm and adapting to the social media logic (Steiner, Magin, \& Stark, 2019; van Dijck \& Poell, 2013), between civic value and shareability (Bell \& Taylor, 2017). More specifically, the social media logic may incentivise lower-quality and softer content (Bell \& Taylor, 2017; Steiner, 2016). Journalists may therefore soften the presentation of their Facebook posts to attract the highest possible attention (Steiner, 2016).

\subsection{Softening of News as a Means of Adapting to the Social Media Logic}

The concept of softening the news describes changes in journalism aimed at attracting audience attention under new competitive pressure (Magin, 2019a; Otto, Glogger, \& Boukes, 2017). Otto et al. (2017) define news softening as a higher-order concept that refers to different levels (e.g., level of media type, news item level or within-item level). Furthermore, news softening represents a multidimensional concept (Esser, 1999; Reinemann, Stanyer, Scherr, \& Legnante, 2012); the different dimensions and indicators form a continuum on the basis of which one can assess the degree of news softening (Reinemann et al., 2012). On the one hand, Reinemann et al. (2012) refer to a distinction between 'hard news,' such as politics, and 'soft news,' such as human interest stories (topic dimension). This dimension refers to the journalistic selection as the first step of the news production process. On the other hand, the authors refer to how the news 
story is presented (news presentation as a second step) in terms of framing (focus dimension, e.g., episodic vs. individual framing) or in terms of verbal and visual style elements (style dimension, e.g., use of emotional language).

Regarding these two steps, journalists have two options of softening the news: They can either 1) select soft news topics instead of hard news topics and/or 2) present them in a softened way (see Figure 1). Since the present study takes only political news into account, it concentrates on only the second option. Journalists adopting this approach can alter the presentation of whole articles or simply the headlines, website teasers or Facebook posts. However, as many people scan news teasers on websites (Costera Meijer \& Groot Kormelink, 2015 ) or the Facebook posts in their newsfeeds (Steiner, Magin, Stark, \& Jürgens, 2019; Vraga, Bode, \& TrollerRenfree, 2016), the latter mode of news softening seems to be most effective in producing audience attention (see also Magin, 2019a; Steiner, 2019). This analysis of news softening therefore focuses on Facebook posts and website teasers (see Figure 1).

Three aspects in particular are pivotal for adapting to the social media logic (see Figure 1). First, the significance of emotionalisation within Facebook has manifested itself within the platform architecture, at the latest with the introduction of 'reactions' in 2016 (Larsson, 2018; Wahl-Jorgensen, 2019). Emotionalising social media content can increase virality (see also Berger \& Milkman, 2012). Second, subjectivity has become more important within social media (Welbers \& Opgenhaffen, 2019): Many Facebook users who share items on Facebook express their feelings about the shared item within their status messages. Subjective items may also increase user engagement (Welbers \& Opgenhaffen, 2019), and users may comment on particularly controversial news items more frequently (Tenenboim \& Cohen, 2015). Although subjectivity is not new to professional journalism, this way of presentation may be a means to increase a news item's virality on Facebook (Welbers \& Opgenhaffen, 2019). The third element is built on the importance of human relations and social media's primary goal of connecting people (van Dijck \& Poell, 2013). This has altered the political logic in that it has "provide[d] new impetus to [its] personalization" (Enli \& Skogerb $\emptyset, 2013$, p. 757). Personalising politics may be relevant not only for political campaigns (Enli \& Skogerb $\varnothing$, 2013) but also for journalistic coverage in which politicians become the "main anchor of interpretation and evaluation" (Otto et al., 2017 , p. 143) of the news. In summary, to adapt to the social media logic, journalists must emotionalise the news and present it in a more subjective and personalised way.

The characteristics explained above comprise two distinct journalistic strategies of news softening (see Figure 1)-applying stylistic features and content-related features (see also Otto et al., 2017). Stylistic features are a means to arouse emotions but without altering the content itself. They refer to the concept of sensationalism (e.g., Uribe \& Gunter, 2007), which can be seen as news softening on the lowest level, the within-item level (Otto et al., 2017). In the present study, affective wording (see Reinemann et al., 2012), one way of emotionalising content, can be assigned to this strategy. An approach centred on content-related features, on the other hand, means that certain aspects are highlighted-which in turn may alter the framework of interpretation of the

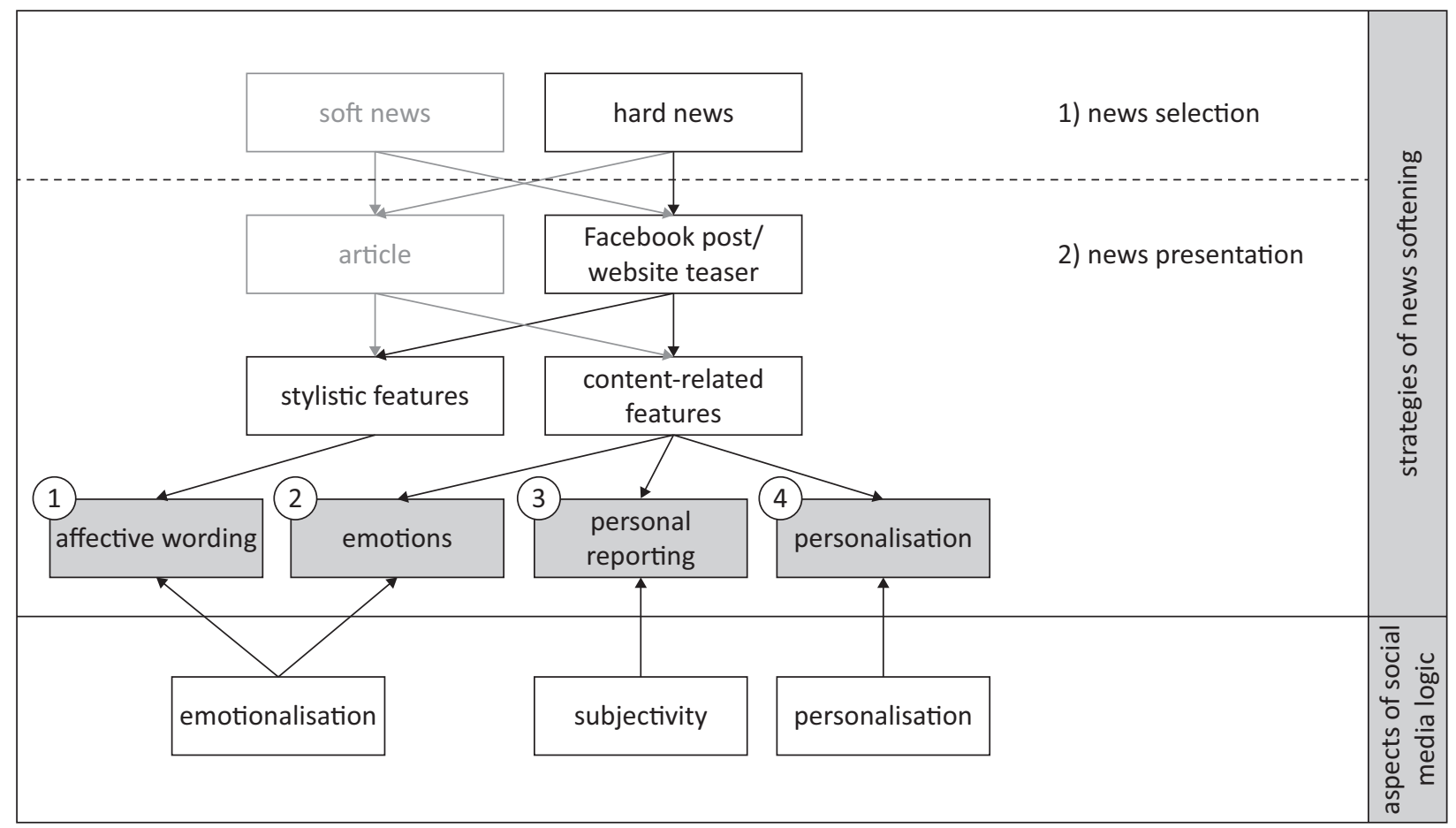

Figure 1. Journalistic news softening strategies. 
whole news item. Thus, this approach operates at the news item level (Otto et al., 2017) and is roughly comparable with the focus dimension of Reinemann et al. (2012). However, while Reinemann et al. (2012) refer to whole articles and their overall framing, even a single sentence or an intentionally used picture can change the interpretation frame within a Facebook post or website teaser. In the present study, both presenting the news in a more subjective way, that is, including the journalist's viewpoint (personal reporting: Reinemann et al., 2012), and highlighting politicians (personalisation) belong to the category of content-related features. In addition, emotionalisation not only refers to stylistic features but also represents a content-related strategy in the sense that journalists may report on emotions within the text or illustrate them in photos. In total, there are four relevant sub-dimensions of news softening (Figure 1): The stylistic feature of 1) affective wording and the contentrelated features of 2) emotions, 3) personal reporting, and 4) personalisation.

First, affective wording includes the use of strong language (including strong verbs and adjectives or superlatives, e.g., 'this is the biggest disaster we've ever had'; Reinemann et al., 2012) but may also refer to emotional metaphors (e.g., 'heart-breaking story'; Leidenberger, 2015). Metaphors can help to construct a mental image to increase the reader's attention (Molek-Kozakowska, 2014) and are thus particularly critical in headlines and website teasers (Wiesinger, 2015) or Facebook posts. Second, reporting on (e.g., 'he was angry/sad') or presenting emotions (e.g., showing crying people) is another central aspect of emotionalisation (Reinemann et al., 2012) and occurs on both the verbal level and the visual level. Although many studies have focused only on verbal indicators (Lefkowitz, 2018; Magin, 2019a), it is essential to consider visual indicators as well (e.g., see Leidenberger, 2015), particularly since visualisation is a key aspect of social media. Third, personal reporting means the appearance of the journalist's point of view; it is the opposite of objective reporting and a central feature of news softening (Reinemann et al., 2012). Fourth, personalisation, another important aspect of news softening (Esser, 1999; Patterson, 2000), focuses on politicians instead of institutions, parties, or issues and emphasises politicians' personal traits, whereby this latter aspect of personal traits has received less research attention (Adam \& Maier, 2010, p. 216; van Aelst, Sheafer, \& Stanyer, 2012). Within Facebook posts and website teasers, journalists can achieve a focus on politicians by showing photographs of them (see Magin, 2019a) or by including evaluative statements by them in the text (for a comparable measurement, see Wilke \& Reinemann, 2001).

\subsection{The Softening of News in Facebook Posts and Website Teasers}

Despite fears that journalistic content on the Internet, and especially on social media, is becoming softer, only a few studies have investigated these concerns. Thus far, most research has focused on the spillover of tabloids' news values on so-called quality or elite newspapers (Esser, 1999; Lefkowitz, 2018; Magin, 2019a) or has compared public service with commercial media outlets (e.g., Donsbach \& Büttner, 2005; Grabe, Zhou, \& Barnett, 2001). Only a few analyses (e.g., Gran, 2015; Karlsson, 2016; Magin, Steiner, Häuptli, Stark, \& Udris, in press) have explored online news softening. Their results indicate a slight increase of news softening online-however, not for all media (Magin et al., in press)-over the course of time or when compared to offline news. Gran (2015) points to a need for further research in the context of social media, such as Facebook, but the few existing studies thereon (Lischka, 2018; Lischka \& Werning, 2017; Magin et al., in press; Steiner, 2016) have not adequately addressed this need.

Lischka and Werning (2017) compared three regional German newspapers in terms of their selection of hard and soft news topics on Facebook and in their print editions. They demonstrated that the analysed outlets spread more soft news on Facebook to increase the reach of the normatively more important hard news. Steiner (2016) compared news softening between German television news on TV and on Facebook and identified differences within the groups of public service and commercial media outlets, finding slightly stronger personalisation by the public service media outlet Tagesschau on Facebook when compared to television. However, the study did not focus solely on Facebook posts but also included the articles linked by them. Another study by Magin et al. (in press) contrasts the German tabloid BILD with the quality newspaper $F A Z$ and discovers opposing trends: While the $F A Z$ is slightly more softened online and on Facebook, news softening for the BILD even slightly decreases compared to its offline news supply. But again, the study analysed the linked articles but did not take into account the Facebook posts themselves. This research gap is addressed by both Lischka (2018) and Hågvar (2019) who focused on soft news presentation strategies in Facebook posts. Based on her quantitative and qualitative surveys of journalists from Finland and Switzerland, Lischka (2018) concluded that emotions, in particular, play a greater role on Facebook than on news websites. However, although the surveyed journalists stated that they sometimes soften hard news to make it more appealing for the audience, they also said that their journalistic standards set boundaries on this. Additionally, Hågvar (2019) used a qualitative content analysis and interviews to detect soft news strategies, such as expressing emotions and using more subjective language, in Norwegian Facebook posts. However, this study analysed only the status messages (i.e., the text at the top of the Facebook post; see Figure 2) of Facebook news posts. Welbers and Opgenhaffen (2019) compared different elements (e.g., status message, headline within link preview) of Facebook posts in their computational content 


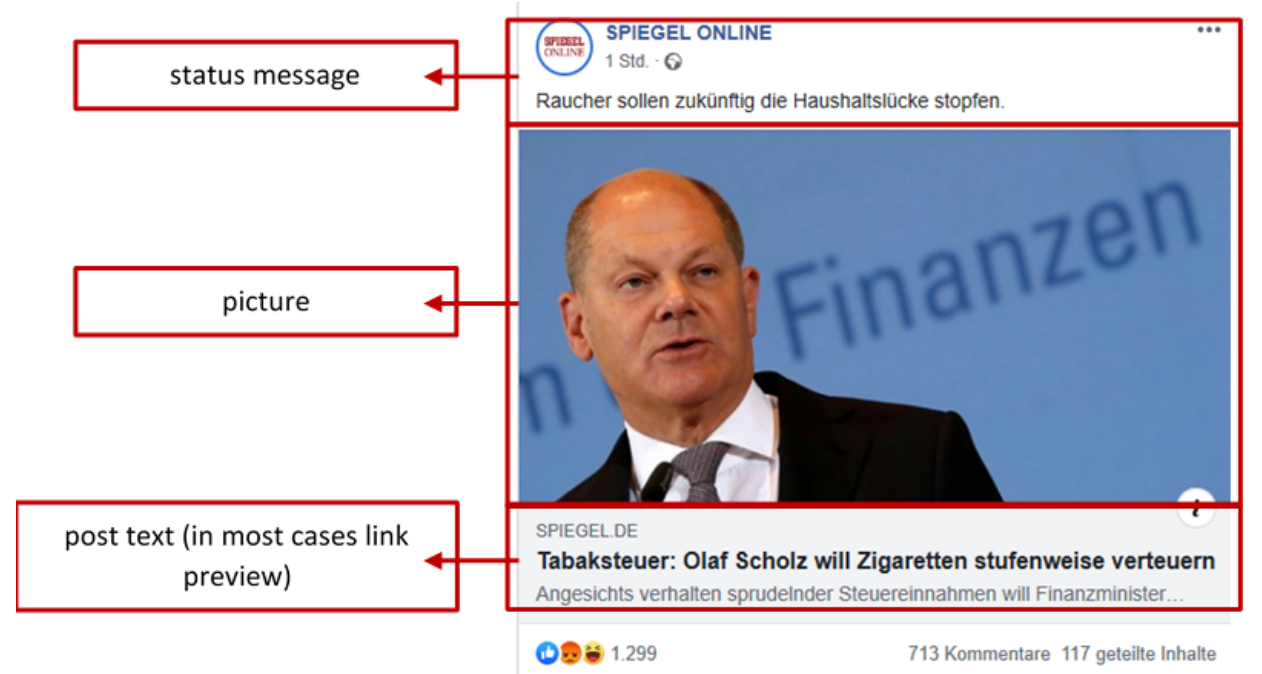

Figure 2. Structure of Facebook posts: Units of analysis. Note: See Welbers and Opgenhaffen (2019, p. 50).

analysis of Belgian and Dutch newspapers, but they restricted their study to a single soft news aspect, the use of subjective language.

Overall, these studies provide first indications of slightly stronger news softening on Facebook compared to traditional and online news outlets as a way of adapting to the social media logic. However, there is still a lack of research examining news softening as a means of altered news presentation while simultaneously taking into account the most important indicators and all elements of Facebook posts (including pictures). In addition, research on news softening in the Facebook posts of German media outlets is missing. Since political news is most critical for strengthening democracy and for which a softened presentation may be more harmful, further research should focus on political news. The present article therefore investigates the following research questions:

RQ1: How softened is political news of German media outlets presented on Facebook?

RQ2: Which sub-dimensions of news softening are most prevalent?

Since news softening may be a means of adapting to the social media logic, journalists may apply news softening to a stronger degree on Facebook than on news websites but corresponding studies that compare both channels are lacking. This article therefore tests the following hypothesis:

$\mathrm{H} 1$ : Website teasers are softened to a lesser degree than Facebook posts.

Furthermore, news softening may also differ between different types of media. While quality and public service media have traditionally been largely secured by a com- paratively high share of subscriptions and public fees, tabloids are predominantly sold at the streets and thus more dependent on attracting the largest possible audience day by day. Thus, news softening can be a strategic journalistic decision with the aim of attracting more audience attention. In this respect, tabloids are generally assumed to apply this strategy to a stronger degree than quality and public service media (e.g., Donsbach \& Büttner, 2005; Lefkowitz, 2018). However, the commercial pressure on the Internet is increasingly reducing these differences. On Facebook, the attention scarcity and therewith competitive pressure is even more pronounced than on websites. The social media logic may therefore promote convergence between these media types, although quality and public service media are assumed to still soften their political news to a lesser degree than tabloid media on Facebook (Magin, 2019b) due to their normative journalistic standards. Thus, the analysis tests the following hypotheses:

H2a: Facebook posts from quality and public service media are softened to a lesser degree than those from tabloid media.

$\mathrm{H} 2 \mathrm{~b}$ : The difference in news softening between quality and public service media, on the one hand, and tabloid media, on the other hand, is smaller on Facebook than on websites.

\section{Method}

To test the hypotheses and answer the research questions, a quantitative content analysis investigated the political 1) Facebook news posts and 2) website teasers of four German media outlets all of which are important representatives of the media types taken into account: one tabloid newspaper (BILD), one quality newspaper (FAZ), one news magazine (Der Spiegel), and one 
public service newscast (Tagesschau). All these outlets have a comparatively high reach on their website and on Facebook and are thus significant news sources for the German population (Newman et al., 2019). Three of these four media outlets can be clearly categorised: Due to its role as an opinion leader for the public and journalists and its high proportion of articles produced inhouse, FAZ is a German quality newspaper (Eilders, 2002; Wilke, 1999). BILD is the most important tabloid, and Tagesschau is the most important public service medium (Newman et al., 2019). Der Spiegel is considered a quality news outlet in the offline sector but is assumed to orient itself toward the popular media in the online sector (Bönisch, 2006).

News items dealing with domestic politics were investigated. The definition of 'domestic politics' includes articles on national politics, articles on regional policy and foreign affairs (when referring to national politics), and pieces on issues of societal interest which could be negotiated in national political institutions (e.g., employment conditions in the health sector, unemployment statistics, food pollution caused by new pesticides).

\subsection{Sample and Collection of Material}

The material was collected over two periods, from the end of May 2018 to the beginning of July 2018 and from mid-September 2018 to the end of October 2018. The selection of these two periods avoids bias due to coverage of specific topics. For the analysis, four weeks were selected from both periods in such a way that parliamentary sitting weeks and non-sitting weeks were included in both periods - under the assumption that the political and with it the media agenda may differ in this respect.

The Facebook posts were stored with the help of Facepager (Jünger \& Keyling, 2019). This program can access IDs of posts via an application programming interface (API). For the coding, this ID was later used to open the Facebook posts in a browser. In order to identify all relevant posts, two coders opened each Facebook post and decided whether it addressed domestic policy according to the above-mentioned criteria. The reliability of this decision was satisfactory, with an average agreement between coders of $94 \%$.

The website teasers were stored automatically using the software Python and Selenium. Specifically, a Firefox browser was programmed to open the homepages of all four media outlets every hour. The computer was programmed to take an automatic screenshot of the entire page, which was then automatically saved as an image file (for a comparable methodological approach, see Jürgens, Stark, \& Magin, 2015). If there were problems loading the website, the page was reloaded in a second or third attempt shortly afterwards. This minimised instances of data loss. Based on the assumption that most teasers are placed on the homepage before they are moved to sub-pages, only the homepage was saved. Similar to the approach used for Facebook, four coders decided which teasers addressed domestic policy and should thus be included in the analysis. They looked at given areas within the homepage (general overview, policy categories) at two-hour intervals from 6 am to $10 \mathrm{pm}$. If there was more than one version of a news teaser-in cases where the journalist changed the headline slightly or chose another picture-the version that included a picture (first criterion) and that was released earliest (second criterion, if there was more than one version including a picture) was chosen. The average agreement between coders, based on all identified screenshots for one day per outlet, was satisfactory at $79 \%$. Due to the large number of relevant website teasers, a random sample was taken from all relevant teasers for each medium.

The final sample includes a total of 1,243 Facebook posts (BILD: $n=148$; FAZ: $n=473$; Der Spiegel: $n=323$; Tagesschau: $n=299$ ) and 1,978 website teasers (BILD: $n=446$; FAZ: $n=583$; Der Spiegel: $n=512$; Tagesschau: $n=437)$.

\subsection{Measurement and Reliability}

The sub-dimension affective wording includes strong language and emotional metaphors (for an overview of all variables see Table 1). The sub-dimension emotions was also measured by two indicators: verbal reporting on emotions and the visual presentation of emotions in photographs (the latter indicator was only used for website teasers and Facebook posts that included pictures). Emotions within photographs were only coded if they were clearly visible. This was important because there are many cases of doubt in this category, as even the neutral facial expression of persons could be interpreted as slightly positive or slightly negative by some coders. For the sub-dimension of personal reporting, the coders decided whether the journalist's point of view appeared in the Facebook post or website teaser. Personalisation was identified with the help of two indicators. First, the coders determined whether the photograph showed a politician (for website teasers and Facebook posts including pictures). If more than one person appeared in the photograph, the coders decided whether one politician was in focus. Second, the coders decided whether an evaluative statement by a politician was included. Here the measurement is based on Wilke and Reinemann (2001), whereby the additional restriction to evaluative statements in this study only takes into account those teasers and posts that are more clearly framed by the perspective of the respective politician (see also Adam \& Maier, 2010), which makes the measurement somewhat stricter. Besides, Wilke and Reinemann (2001) also measure the length of the statements, which makes little sense given the already limited text within Facebook posts and website teasers.

The coding distinguished between three units of analysis. For Facebook posts (see Figure 2), these units were 1 ) the status message, 2) the post text (all other text included in the Facebook post, which in most cases meant 
Table 1. Overview of sub-dimensions and the measurement of related indicators.

\begin{tabular}{|c|c|c|c|c|}
\hline Sub-dimension & Indicator (coding) & $\begin{array}{l}\text { Units of analysis } \\
\text { (number) }\end{array}$ & $\begin{array}{l}\text { Standardisation of } \\
\text { value range/ } \\
\text { calculation of index }\end{array}$ & $\begin{array}{l}\text { Inter-coder reliability } \\
\text { (Brennan-Prediger's } \\
\text { kappa) }\end{array}$ \\
\hline \multirow[t]{3}{*}{$\begin{array}{l}\text { Affective } \\
\text { wording }\end{array}$} & Strong language $(0 / 1)$ & $\begin{array}{l}\text { Status message } \\
\text { and post } \\
\text { text/headline } \\
\text { and lead ( } 2 \text { ) }\end{array}$ & Sum of values/2 & .76 \\
\hline & Emotional metaphors $(0 / 1)$ & $\begin{array}{l}\text { Status message } \\
\text { and post } \\
\text { text/headline } \\
\text { and lead ( } 2 \text { ) }\end{array}$ & Sum of values/2 & .88 \\
\hline & Sub-index affective wording & & $\begin{array}{l}\text { Sum of values of } \\
\text { both indicators } / 2\end{array}$ & \\
\hline \multirow[t]{3}{*}{ Emotions } & Reporting on emotions $(0 / 1)$ & $\begin{array}{l}\text { Status message } \\
\text { and post } \\
\text { text/headline } \\
\text { and lead (2) }\end{array}$ & Sum of values/2 & .93 \\
\hline & Presenting emotions $(0 / 1)$ & Picture (1) & Original value & .85 \\
\hline & Sub-index emotions & & $\begin{array}{l}\text { Sum of values of } \\
\text { both indicators } / 2\end{array}$ & \\
\hline $\begin{array}{l}\text { Personal } \\
\text { reporting }\end{array}$ & Journalists' points of view $(0 / 1)$ & $\begin{array}{l}\text { Status message } \\
\text { and post } \\
\text { text/headline } \\
\text { and lead ( } 2 \text { ) }\end{array}$ & Sum of values/2 & .67 \\
\hline \multirow[t]{3}{*}{ Personalisation } & Photo with politician (0/1) & Picture (1) & Original value & $\begin{array}{l}.71 \text { (identification } \\
\text { person); } \\
.93 \text { (identification } \\
\text { politician) }\end{array}$ \\
\hline & $\begin{array}{l}\text { Evaluative statement from } \\
\text { politician }(0 / 1)\end{array}$ & $\begin{array}{l}\text { Facebook } \\
\text { post/website } \\
\text { teaser (1) }\end{array}$ & Original value & .86 \\
\hline & Sub-index personalisation & & $\begin{array}{l}\text { Sum of values of } \\
\text { both indicators } / 2\end{array}$ & \\
\hline Index total & & & $\begin{array}{l}\text { Sum of all sub- } \\
\text { dimensions } / 4\end{array}$ & \\
\hline
\end{tabular}

the text in the link preview), and 3) the picture. For website teasers (see Figure 3 ), these units were 1 ) the headline, 2) the lead text, and 3) the picture. All indicators were binary coded $(0 / 1=$ not appearing/appearing within the respective unit of analysis). The visual indicators were coded with regard to one unit of analysis (the picture of the Facebook post/the website teaser). The verbal indicators were coded with regard to two units of analysis (the status message and post text, or the headline and lead; see Table 1). Only the evaluative statements from politicians were not analysed separately for two units of analysis. Here, separate coding was diffi- cult to achieve, for example, because the statements extended over several units of analysis or because statements in one unit of analysis were assigned to the party and, in another, to the politician. For all indicators that were coded with regard to two units of analysis, both values were summed. To improve the comparability of the indicators, this sum was then standardised (see Table 1) to a value range from 0 (not present at all; no softening) to 1 (present within both units of analysis; strongest possible softening).

For each sub-dimension that included more than one indicator, the values of the indicators were averaged into 


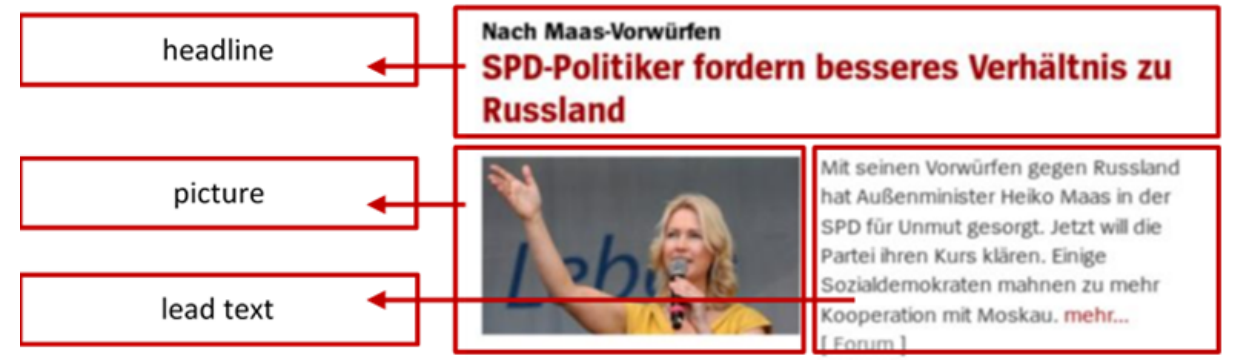

Figure 3. Structure of website teaser: Units of analysis.

a sub-index. The sub-indices from all sub-dimensions were then again averaged into an overall index. Again, the values of this index range from 0 (no features at all; not softened at all) to 1 (all features used to the greatest possible extent; completely softened).

Three coders completed the coding of the Facebook news posts and website teasers. The reliability of their coding was tested using Brennan-Prediger's kappa. This coefficient is chance-corrected and more robust than Krippendorff's alpha regarding variables with a skewed distribution (Quarfoot \& Levine, 2016). Reliability coefficients were perfect (1.00) for formal variables (ID, outlet) and very good or at least satisfactory (between 0.67 and 0.93, see Table 1) for all other variables.

\section{Results}

This section first concentrates on news softening in Facebook posts (RQ1) and examines different subdimensions in greater detail (RQ2). The analysis then contrasts Facebook posts with website teasers $(\mathrm{H} 1)$ and hereby additionally focuses on the difference between quality and public service media outlets, on the one hand, and tabloid media outlets, on the other hand $(\mathrm{H} 2)$.

\subsection{Softening of News in Political Facebook Posts}

To answer RQ1 and RQ2, ANOVAs were run for each indicator, each sub-index, and the overall index. Table 2 shows the mean values for each media outlet. At first glance, the values suggest a low to medium level of news softening (RQ1). A further examination reveals that for more than two-thirds of the posts, the softening value is below 0.30 ; only $1 \%$ of all Facebook posts have values above 0.60 . This means that most Facebook posts are moderately softened.

Considering the individual sub-dimensions (RQ2) reveals clear differences. While emotions are seldom presented or reported on, personalisation is the most important aspect of news softening and seems to be a rather common journalistic strategy across all outlets. The visual aspect-showing politicians in photographs-

Table 2. Comparison of Facebook posts regarding news softening.

\begin{tabular}{|c|c|c|c|c|}
\hline Mean values & $\begin{array}{c}\text { Facebook BILD } \\
(\mathrm{A} ; n=148)\end{array}$ & $\begin{array}{c}\text { Facebook } F A Z \\
(\mathrm{~B} ; n=473)\end{array}$ & $\begin{array}{l}\text { Facebook Der Spiegel } \\
\qquad(C ; n=323)\end{array}$ & $\begin{array}{l}\text { Facebook Tagesschau } \\
\text { (D; } n=299)\end{array}$ \\
\hline Reporting on emotions & .05 & .04 & .04 & .04 \\
\hline Presenting emotions ${ }^{1}$ & .13 & .10 & .08 & .06 \\
\hline Sub-index emotions & .09 & .07 & .06 & .05 \\
\hline Emotional metaphors & .11 & .09 & .11 & .09 \\
\hline Strong language & $.29^{B, D}$ & .18 & $.27^{\mathrm{B}, \mathrm{D}}$ & .15 \\
\hline Sub-index affective wording & $.20^{\mathrm{b}, \mathrm{D}}$ & .14 & $.19^{\mathrm{B}, \mathrm{D}}$ & .12 \\
\hline Statements from politicians & .26 & .33 & .35 & $.42^{A, b}$ \\
\hline Showing politicians in photos ${ }^{1}$ & .46 & .53 & $.60^{\mathrm{D}}$ & .46 \\
\hline Sub-index personalisation & .36 & .43 & $.47^{a}$ & .44 \\
\hline Sub-index personal reporting & $.27^{\mathrm{b}, \mathrm{D}}$ & $.18^{\mathrm{D}}$ & $.23^{\mathrm{D}}$ & .10 \\
\hline Index total & $.23^{\mathrm{D}}$ & .20 & $.24^{\mathrm{B}, \mathrm{D}}$ & .18 \\
\hline
\end{tabular}

Notes: ${ }^{A a}=$ The letters following the values indicate from what other values the respective value significantly differs (ANOVA post-hoc tests; lowercase letters: $p<0.05$, uppercase letters: $p<0.01) .^{1}=$ For this analysis, only Facebook posts that contained pictures were used; in the case of Facebook BILD and Facebook Der Spiegel, there were a few missing cases due to the pictures' deletion before the Facebook post was coded: Facebook BILD $n=126$; Facebook FAZ $n=473$; Facebook Der Spiegel $n=314$; Facebook Tagesschau $n=297$. 
is, however, somewhat more pronounced within this sub-dimension. Compared to this, the degree of personal reporting is rather low to medium-high for all outlets, with a significantly lower value for Tagesschau.

Regarding the emotionalisation of Facebook posts, there are clear differences between reporting on and presenting emotions versus affective wording. Indicators of the first sub-dimension rarely occur. This is particularly true for verbal reporting on emotions, which may be more appropriate and more common in human interest stories than in political news. Affective wording, which refers to stylistic features, is used to a greater extent, with strong language being more common than metaphors.

In summary, the overall index of news softening on Facebook is increased primarily by personalisation, but affective wording and personal reporting still play comparatively large roles.

\subsection{Difference in News Softening of Facebook Posts and Website Teasers}

Having examined news softening on Facebook, the analysis next considers whether the degree of news softening is higher on Facebook than on news websites $(\mathrm{H} 1)$ and the extent to which quality and public service media differ from tabloid media in this regard $(\mathrm{H} 2 \mathrm{a}, \mathrm{H} 2 \mathrm{~b})$.
Regarding $\mathrm{H} 1$, t-tests were performed to examine the mean differences between the website teasers and Facebook posts for each medium and each indicator. The data presented in Table 3 confirm $\mathrm{H} 1$ only for BILD and Der Spiegel. For BILD, the higher degree of news softening can be attributed mainly to a greater use of strong language and a higher degree of personal reporting. Due to a higher degree of (visual) personalisation within website teasers, the difference in the overall index is nevertheless minor. Facebook posts of Der Spiegel also contain significantly more emotional language (strong language), but they additionally refer more often to evaluative statements of politicians than website teasers. Again, the overall difference is slight, as the other indicators hardly differ.

As with BILD and Der Spiegel, news softening in the posts of Tagesschau is somewhat more pronounced on Facebook, but not to a significant degree. The Facebook posts contain significantly more evaluative statements from politicians, while all other indicators are not or hardly used more frequently compared to the website teasers. In the case of $F A Z$, significant differences can only be identified for the use of strong language and the presentation of emotions in photos (although emotions are still presented quite seldom).

This outcome indicates that while news softening may be a means to adapt to the social media logic, particularly

Table 3. Comparison of website teasers and Facebook posts regarding news softening.

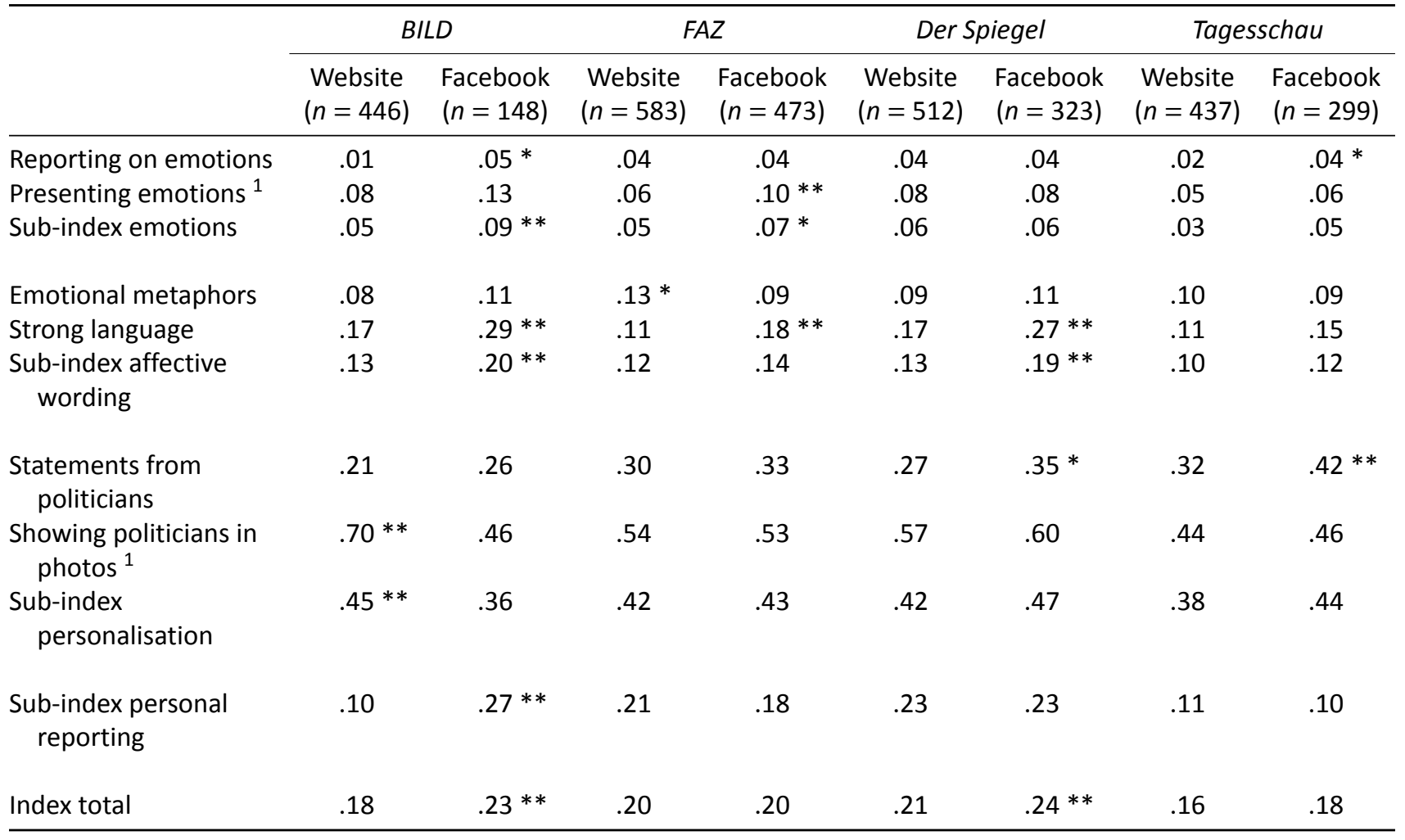

Notes: ${ }^{1}=$ For this analysis, only Facebook posts and website teasers that contained pictures were used; in the case of Facebook $B I L D$ and Facebook Der Spiegel, there were a few missing cases due to the pictures' deletion before the Facebook post was coded: bild.de $n=377$, Facebook BILD $n=126$; faz.net $n=530$, Facebook FAZ $n=473$; spiegel.de $n=424$, Facebook Der Spiegel $n=314$; tagesschau. de $n=437$, Facebook Tagesschau $n=297 .{ }^{*} p<.05, * * p<.01$ (t-tests). 
quality and public service media outlets hardly use this strategy. Regarding the indicators, the stylistic feature of strong language and references to evaluative statements by politicians are more widely used on Facebook. By contrast, the values for showing politicians in pictures hint at a ceiling effect, meaning that this aspect already plays such a major role on media outlets' websites that it could hardly be further increased on Facebook.

In the next step, ANOVAs were conducted for comparing website teasers and Facebook posts to determine whether quality and public service media use less softening within Facebook ( $\mathrm{H} 2 \mathrm{a}$ ) and whether the difference between these outlets and tabloid media decreases on Facebook (H2b).

Table 4 partially confirms $\mathrm{H} 2 \mathrm{a}$. Post-hoc tests show that Facebook posts of BILD are presented in a sig- nificantly more softened manner than those from Tagesschau, whereas the difference between BILD and $F A Z$ is smaller and non-significant. Der Spiegel, which cannot be clearly categorised as a quality or tabloid medium, provides content that is even slightly more softened than that of $B I L D$. Particularly strong language is used to a significantly higher degree by Der Spiegel and BILD than by FAZ and Tagesschau. For personal reporting, Tagesschau Facebook posts have a considerably lower value than those from all other outlets. Overall, however, the differences between the media outlets are relatively small.

Comparing Facebook with the websites reveals even slightly smaller differences among the media outlets for the website teasers. While BILD and Der Spiegel website teasers are still significantly more softened than Tagesschau website teasers, the overall value of $F A Z$ is

Table 4. Comparison of Facebook posts and website teasers regarding news softening.

\begin{tabular}{|c|c|c|c|c|c|c|c|c|}
\hline \multirow[b]{2}{*}{ Mean values } & \multicolumn{4}{|c|}{ Facebook } & \multicolumn{4}{|c|}{ Website } \\
\hline & $\begin{array}{c}B I L D \\
(\mathrm{~A} ; n=148)\end{array}$ & $\begin{array}{c}F A Z \\
(B ; n=473)\end{array}$ & $\begin{array}{l}\text { Der Spiegel } \\
(C ; n=323)\end{array}$ & $\begin{array}{l}\text { Tagesschau } \\
(\mathrm{D} ; n=299)\end{array}$ & $\begin{array}{c}B I L D \\
(\mathrm{~A} ; n=446)\end{array}$ & $\begin{array}{c}F A Z \\
(B ; n=583)\end{array}$ & $\begin{array}{c}\text { Der Spiegel } \\
(C ; n=512)\end{array}$ & $\begin{array}{l}\text { Tagesschau } \\
(\mathrm{D} ; n=437)\end{array}$ \\
\hline $\begin{array}{l}\text { Reporting on } \\
\text { emotions }\end{array}$ & .05 & .04 & .04 & .04 & .01 & $.04^{\mathrm{a}}$ & $.04^{\mathrm{A}}$ & .02 \\
\hline $\begin{array}{l}\text { Presenting } \\
\text { emotions }\end{array}$ & .13 & .10 & .08 & .06 & .08 & .06 & .08 & .05 \\
\hline $\begin{array}{l}\text { Sub-index } \\
\text { emotions }\end{array}$ & .09 & .07 & .06 & .05 & .05 & .05 & $.06^{d}$ & .03 \\
\hline $\begin{array}{l}\text { Emotional } \\
\text { metaphors }\end{array}$ & .11 & .09 & .11 & .09 & .08 & $.13^{\mathrm{A}}$ & .09 & .10 \\
\hline $\begin{array}{l}\text { Strong } \\
\quad \text { language }\end{array}$ & $.29^{\mathrm{B}, \mathrm{D}}$ & .18 & $.27^{\mathrm{B}, \mathrm{D}}$ & .15 & $.17^{\mathrm{B}, \mathrm{D}}$ & .11 & $.17^{\mathrm{B}, \mathrm{D}}$ & .11 \\
\hline $\begin{array}{l}\text { Sub-index } \\
\text { affective } \\
\text { wording }\end{array}$ & $.20^{b, D}$ & .14 & $.19^{\mathrm{B}, \mathrm{D}}$ & .12 & .13 & .12 & .13 & .10 \\
\hline $\begin{array}{l}\text { Statements } \\
\text { from } \\
\text { politicians }\end{array}$ & .26 & .33 & .35 & $.42^{\mathrm{A}, \mathrm{b}}$ & .21 & $.30^{A}$ & .27 & $.32^{A}$ \\
\hline $\begin{array}{l}\text { Showing } \\
\text { politicians } \\
\text { in photos }^{1}\end{array}$ & .46 & .53 & $.60^{\mathrm{D}}$ & .46 & $.70^{B, C, D}$ & $.54^{d}$ & $.57^{\mathrm{D}}$ & .44 \\
\hline $\begin{array}{l}\text { Sub-index } \\
\text { personali- } \\
\text { sation }\end{array}$ & .36 & .43 & $.47^{\mathrm{a}}$ & .44 & $.45^{d}$ & .42 & .42 & .38 \\
\hline $\begin{array}{l}\text { Sub-index } \\
\text { personal } \\
\text { reporting }\end{array}$ & $.27^{\mathrm{b}, \mathrm{D}}$ & $.18^{\mathrm{D}}$ & $.23^{\mathrm{D}}$ & .10 & .10 & $.21^{\mathrm{A}, \mathrm{D}}$ & $.23^{A, D}$ & .11 \\
\hline Index total & $.23^{\mathrm{D}}$ & .20 & $.24^{\mathrm{B}, \mathrm{D}}$ & .18 & $.18^{d}$ & $.20^{\mathrm{D}}$ & $.21^{\mathrm{a}, \mathrm{D}}$ & .16 \\
\hline
\end{tabular}

Notes: ${ }^{\text {Aa }}=$ The letters following the values indicate from what other values the respective value significantly differs (ANOVA post-hoc tests; lowercase letters: $p<0.05$, uppercase letters: $p<0.01$ ). ${ }^{1}=$ For this analysis, only Facebook posts and website teasers that contained pictures were used; in the case of Facebook BILD and Facebook Der Spiegel, there were a few missing cases due to the pictures' deletion before the Facebook post was coded: bild.de $n=377$, Facebook BILD $n=126$; faz.net $n=530$, Facebook FAZ $n=473$; spiegel.de $n=424$, Facebook Der Spiegel $n=314$; tagesschau.de $n=437$, Facebook Tagesschau $n=297$. 
even slightly higher than that of $B I L D . \mathrm{H} 2 \mathrm{~b}-$ which assumes converging trends between quality and public service media, on the one hand, and tabloid media, on the other hand, can thus be rejected. Rather, BILD and Der Spiegel are the outlets that seem to adjust to the social media logic in a stronger way-as already described with regard to $\mathrm{H} 1$-thus slightly widening the gap between quality or public service and tabloid media.

\section{Conclusions}

Since Facebook is a relevant news source for many people (Newman et al., 2019), journalists provide content on that platform to reach a wider audience. However, because Facebook users' engagement with published content largely determines that content's visibility (Bucher, 2012; DeVito, 2017), journalists seek to attract the highest possible attention on this platform. This situation has given rise to fears that journalists will lower their normative quality standards according to the social media logic, as softening the news is a suitable means of attracting the audience's attention, but research on news softening on Facebook is lacking. This study examines news softening in the political Facebook posts of four German media outlets. It also compares these Facebook posts with website teasers from the same media outlets to determine whether news softening is indeed stronger on Facebook than on news websites: That outcome would indicate that journalists have used news softening to adapt to the social media logic. The study also examines whether differences between media outlets converge on Facebook.

The results show that the overall degree of news softening is low to medium across all outlets. Personalisation is the most pronounced sub-dimension in the Facebook posts of all outlets, while other aspects, such as reporting on or presenting emotions, occur comparatively rarely. Furthermore, the comparison of Facebook posts with website teasers shows that only BILD and Der Spiegel have considerably intensified news softening on Facebook, particularly with regard to affective wording, which leads to a slightly greater difference between these outlets and the quality and public service outlets on Facebook.

The fear that political news posts on Facebook are extremely softened and thus not able to fulfil their information function is therefore exaggerated. Although journalists apply news softening to some extent to increase the attention of Facebook users, they maintain their normative quality standards. However, measuring news softening only on the basis of political news is a quite restrictive approach. To obtain a complete picture, studies should not only examine news softening in terms of an altered presentation of political news but at the same time also in terms of topic selection, that is, the share of hard and soft news which may be another consequence of increased audience orientation on social media (see Lischka \& Werning, 2017). Moreover, to fully assess the degree of news softening and its impact on democracy, one must also consider the actual effect of news softening on people's information processing and knowledge. This effect may be different on Facebook, where the context-which includes entertaining and non-journalistic posts-is different than on news outlets' websites. Heiss and Matthes (2019) made a promising first step in this direction with related experiments suggesting that a humorous context can intensify attention on political posts. Future studies should further investigate whether these posts are also read and clicked on, whether a softened presentation of political posts will further intensify the attention paid to the respective news post and whether a softened news post is perceived differently within this specific information environment than within a news website.

The comparison of website teasers with Facebook posts challenges the assumption that the social media logic results in overall increased news softening, at least at first glance. The quality and public service outlets in particular do not soften their news to a significantly greater extent on Facebook compared to their websites. There are several explanations for this finding. The most obvious is that the normative quality standards of these media outlets prevent strong adjustment, which would confirm Lischka's (2018) finding that these norms put limits on news softening. Beyond that justification, another possibility is that the adaptation of news to the social media logic is not limited to social media platforms but also manifests in other contexts, including outlets' websites. Thus, a stronger adaptation to the social media logic would result in more intense news softening of both Facebook posts and website teasers; this might also explain the lack of differences between Facebook posts and website teasers. However, this interpretation is speculative as this question is beyond the scope of this study. Assessing this possibility would require comparative website data from previous years and additional qualitative interviews with journalists. Finally, news softening may be stronger on Facebook, but the traditional indicators used here cannot measure this. In other words, the means of softening news may be changing on Facebook so that the traditional measurement approach is no longer valid. Elements particularly used on social media, such as the use of emoticons (Welbers \& Opgenhaffen, 2019) or clickbait (Blom \& Hansen, 2015), may additionally contribute to news softening (see also Hågvar, 2019) and should therefore be considered in future research.

Furthermore, although there seems to be no convergence on Facebook between media types, the differences between these media outlets are still surprisingly small with regard to both Facebook posts and website teasers. The small differences suggest that there may already be converging trends on the websites. Moreover, these small differences may also be country-specific. In Germany, quality and tabloid media traditionally differ less than for example in the UK (Esser, 1999) and the news softening trend tends to be weaker as well than 
in the Anglo-American system (Umbricht \& Esser, 2016). Comparative research might thus help here to better interpret these country-specific results.

Besides, the small differences may also point to one limitation of the study: Although the indicators were coded in as much detail as possible and with regard to several units of analysis, the coding was binary. This approach may have resulted in existing variance (e.g., different degrees of strong language) not being coded. An appropriate coding approach based on a more detailed scale, as is possible in journalistic articles, would, however, be difficult to implement with regard to website teasers and Facebook posts due to the small amount of text. This is also the reason why some indicators (e.g., for personalisation) are quite superficial.

Nevertheless, the present study is an important first step in research on news softening on Facebook. Future research should improve and adapt the measurement of news softening for new information environments. Furthermore, research shows that younger audiences are increasingly turning to Instagram or WhatsApp (Newman et al., 2019) for news, which is why future studies should also focus on these platforms. In this way, research can react to current developments, draw a complete picture of how strongly news is softened on social media, and determine the extent to which audiences who consume news there are well-informed.

\section{Acknowledgments}

Many thanks go to my coders Lea Lothwesen, Tanja Mager and Julian Schlag, as well as to Max Leffer and Anna Vezirgenidi, who supported me in identifying relevant Facebook posts and website teasers. Many thanks also to the research program 'Media Convergence,' located at the Johannes Gutenberg University Mainz, that funded the project.

\section{Conflict of Interests}

The author declares no conflict of interests.

\section{References}

Adam, S., \& Maier, M. (2010). Personalization of politics: A critical review and agenda for research. Annals of the International Communication Association, 34(1), 213-257.

Bell, E., \& Taylor, O. (2017). The platform press: How Silicon Valley reengineered journalism. New York, NY: Tow Center for Digital Journalism.

Berger, J., \& Milkman, K. L. (2012). What makes online content viral? Journal of Marketing Research, 49(2), 192-205.

Blom, J. N., \& Hansen, K. R. (2015). Click bait: Forwardreference as lure in online news headlines. Journal of Pragmatics, 76, 87-100.

Bönisch, J. (2006). Meinungsführer oder Populärmedi- um? Das journalistische Profil von Spiegel Online [Opinion leader or popular medium? The journalistic profile of Spiegel Online]. Berlin and Münster: LIT.

Bucher, T. (2012). Want to be on the top? Algorithmic power and the threat of invisibility on Facebook. New Media \& Society, 14(7), 1164-1180.

Cherubini, F., \& Nielsen, R. K. (2016). Editorial analytics: How news media are developing and using audience data and metrics. SSRN Electronic Journal. Retrieved from https://papers.ssrn.com/sol3/ papers.cfm?abstract_id=2739328

Costera Meijer, I., \& Groot Kormelink, T. (2015). Checking, sharing, clicking and linking: Changing patterns of news use between 2004 and 2014. Digital Journalism, 3(5), 664-679.

DeVito, M. A. (2017). From editors to algorithms: A values-based approach to understanding story selection in the Facebook news feed. Digital Journalism, 5(6), 753-773.

Donsbach, W., \& Büttner, K. (2005). Boulevardisierungstrend in deutschen Fernsehnachrichten: Darstellungsmerkmale der Politikberichterstattung vor den Bundestagswahlen 1983, 1990 und 1998 [Trends of tabloidization in German TV news: How the news broadcast presented politics before the general elections in 1983, 1990, and 1998]. Publizistik, 50(1), 21-38.

Eilders, C. (2002). Conflict and consonance in media opinion: Political positions of five German quality newspapers. European Journal of Communication, 17(1), 25-63.

Enli, G. S., \& Skogerb $\varnothing$, E. (2013). Personalized campaigns in party-centred politics: Twitter and Facebook as arenas for political communication. Information, Communication \& Society, 16(5), 757-774.

Esser, F. (1999). 'Tabloidization' of news: A comparative analysis of Anglo-American and German press journalism. European Journal of Communication, 14(3), 291-324.

Grabe, M. E., Lang, A., \& Zhao, X. (2003). News content and form: Implications for memory and audience evaluations. Communication Research, 30(4), 387-413.

Grabe, M. E., Zhou, S., \& Barnett, B. (2001). Explicating sensationalism in television news: Content and the bells and whistles of form. Journal of Broadcasting \& Electronic Media, 45(4), 635-655.

Graber, D. A. (1994). The infotainment quotient in routine television news: A director's perspective. Discourse \& Society, 5(4), 483-508.

Gran, C. S. (2015). Tabloidisation of the Norwegian news media: A quantitative analysis of print and online newspaper platforms (Unpublished Doctoral dissertation). University of London, London, UK. Retrieved from http://www.lse.ac.uk/media-andcommunications/assets/documents/research/mscdissertations/2014/Celine-Storstad-Gran-LSEMediaSeries-AF.pdf 
Hågvar, Y. B. (2019). News media's rhetoric on Facebook. Journalism Practice, 13(7), 853-872.

Heiss, R., \& Matthes, J. (2019). Funny cats and politics: Do humorous context posts impede or foster the elaboration of news posts on social media? Communication Research. Advance online publication. https:// doi.org/10.1177/0093650219826006

Jünger, J., \& Keyling, T. (2019). Facepager: An application for automated data retrieval on the web. Github. Retrieved from https://github.com/strohne/Facepager

Jürgens, P., Stark, B., \& Magin, M. (2015). Messung von Personalisierung in computervermittelter Kommunikation [Measuring personalization effects in computer-mediated communication]. In A. Maireder, J. Ausserhofer, C. Schumann, \& M. Taddicken (Eds.), Digitale Methoden in der Kommunikationswissenschaft [Digital methods in communication science] (pp. 251-270). Berlin: Freie Universität Berlin, Institut für Publizistik- und Kommunikationswissenschaft. https://doi.org/10.17174/dcr.v2.11

Karlsson, M. B. (2016). Goodbye politics, hello lifestyle: Changing news topics in tabloid, quality and local newspaper websites in the U.K. and Sweden from 2002 to 2012. Observatorio, 10(4), 150-165.

Larsson, A. O. (2018). Diversifying likes: Relating reactions to commenting and sharing on newspaper Facebook pages. Journalism Practice, 12(3), 326-343.

Lefkowitz, J. (2018). "Tabloidization" or dualconvergence: Quoted speech in tabloid and "quality" British newspapers 1970-2010. Journalism Studies, 19(3), 353-375.

Leidenberger, J. (2015). Boulevardisierung von Fernsehnachrichten: Eine Inhaltsanalyse deutscher und französischer Hauptnachrichtensendungen [Tabloidization of TV news: A content analysis of German and French main newscasts]. Wiesbaden: Springer.

Lischka, J. A. (2018). Logics in social media news making: How social media editors marry the Facebook logic with journalistic standards. Journalism. Advance online publication. https://doi.org/10.1177/ 1464884918788472

Lischka, J. A., \& Werning, M. (2017). Wie Facebook den Regionaljournalismus verändert: Publikumsund Algorithmusorientierung bei der FacebookThemenselektion von Regionalzeitungen [How Facebook alters regional journalism: Audience and algorithm orientation in the Facebook topic selection of regional newspapers]. kommunikation@gesellschaft, 18, 1-25.

Magin, M. (2019a). Attention, please! Structural influences on tabloidization of campaign coverage in German and Austrian elite newspapers (1949-2009). Journalism, 20(12), 1704-1724.

Magin, M. (2019b). Elite versus popular press. In T. P. Vos, F. Hanusch, D. Dimitrakopoulou, M. GeertsemaSligh, \& A. Sehl (Eds.), The international encyclopedia of journalism studies. Hoboken, NJ: Wiley-Blackwell. https://doi.org/10.1002/9781118841570.iejs0226

Magin, M., Steiner, M., Häuptli, A., Stark, B., \& Udris, L. (in press). Is Facebook driving tabloidization? A crosschannel comparison of two German newspapers. In M. Conboy \& S. A. Eldridge, II (Eds.), Global tabloid: Culture and technology. Abingdon: Routledge.

Molek-Kozakowska, K. (2014). Coercive metaphors in news headlines: A cognitive-pragmatic approach. Brno Studies in English, 40(1), 149-173.

Newman, N., Fletcher, R., Kalogeropoulos, A., \& Nielsen, R. K. (2019). Reuters Institute digital news report 2019. Oxford: Reuters Institute for the Study of Journalism.

Otto, L., Glogger, I., \& Boukes, M. (2017). The softening of journalistic political communication: A comprehensive framework model of sensationalism, soft news, infotainment, and tabloidization. Communication Theory, 27(2), 136-155.

Patterson, T. E. (2000). Doing well and doing good (KSG Working Paper No. 01-001). Cambridge, MA: Joan Shorenstein Center on the Press, Politics and Public Policy.

Quarfoot, D., \& Levine, R. A. (2016). How robust are multirater interrater reliability indices to changes in frequency distribution? The American Statistician, 70(4), 373-384.

Reinemann, C., Stanyer, J., Scherr, S., \& Legnante, G. (2012). Hard and soft news: A review of concepts, operationalizations and key findings. Journalism, 13(2), 221-239.

Steiner, M. (2016). Boulevardisierung goes Facebook? Ein inhaltsanalytischer Vergleich politischer Nachrichten von tagesschau, heute, RTL Aktuell und Sat.1 Nachrichten im Fernsehen und auf Facebook [Tabloidization goes Facebook? A comparative content analysis of the news quality of tagesschau, heute, RTL Aktuell und Sat.1 on TV and on Facebook]. In L. Leißner, H. Bause, \& L. Hagemeyer (Eds.), Politische Kommunikation: neue Phänomene, neue Perspektiven, neue Methoden [Political communication: New phenomena, new perspectives, new methods] (pp. 27-46). Berlin: Frank \& Timme.

Steiner, M. (2019). Re-evaluating the concept of 'softening the news' in the platform society. Paper presented at the ECREA Political Communication Conference 2019 "Transforming Communication: Old and New Borders," Poznan, Poland.

Steiner, M., Magin, M., \& Stark, B. (2019). Uneasy bedfellows: Comparing the diversity of German public service news on television and on Facebook. Digital Journalism, 7(1), 100-123.

Steiner, M., Magin, M., Stark, B., \& Jürgens, P. (2019). Aus Versehen informiert? Facebooks Bedeutung für die Nachrichtennutzung nebenbei-eine Mehrmethoden-Analyse [Accidentally informed? Facebook's importance for incidental news consumption-A multi-method analysis]. In P. Weber, F. Mangold, M. Hofer, \& T. Koch (Eds.), 
Meinungsbildung in der Netzöffentlichkeit [Opinion formation in the digital public sphere] (pp. 19-36). Baden-Baden: Nomos.

Tandoc, E. C. (2015). Why web analytics click: Factors affecting the ways journalists use audience metrics. Journalism Studies, 16(6), 782-799.

Tenenboim, O., \& Cohen, A. A. (2015). What prompts users to click and comment: A longitudinal study of online news. Journalism, 16(2), 198-217.

Umbricht, A., \& Esser, F. (2016). The push to popularize politics: Understanding the audience-friendly packaging of political news in six media systems since the 1960s. Journalism Studies, 17(1), 100-121.

Uribe, R., \& Gunter, B. (2007). Are 'sensational' news stories more likely to trigger viewers' emotions than non-sensational news stories? A content analysis of British TV news. European Journal of Communication, 22(2), 207-228.

van Aelst, P., Sheafer, T., \& Stanyer, J. (2012). The personalization of mediated political communication: A review of concepts, operationalizations and key findings. Journalism, 13(2), 203-220.

van Dijck, J., \& Poell, T. (2013). Understanding social media logic. Media and Communication, 1(1), 2-14.

Vraga, E., Bode, L., \& Troller-Renfree, S. (2016). Beyond self-reports: Using eye tracking to measure topic and style differences in attention to social media content. Communication Methods and Measures, 10(2-3), 149-164.

$\mathrm{Vu}, \mathrm{H}$. T. (2014). The online audience as gatekeeper: The influence of reader metrics on news editorial selection. Journalism, 15(8), 1094-1110.

Wahl-Jorgensen, K. (2019). Emotions, media and politics. Cambridge and Medford, MA: Polity Press.

Welbers, K., \& Opgenhaffen, M. (2019). Presenting news on social media. Media logic in the communication style of newspapers on Facebook. Digital Journalism, 7(1), 45-62.

Wiesinger, A. (2015). Boulevardzeitungen im crossmedialen Vergleich: Inhalte und Gestaltung des populären Journalismus [Tabloid papers in crossmedia comparison: Content and style of popular journalism]. Innsbruck: Innsbrucker University Press.

Wilke, J. (1999). Leitmedien und Zielgruppenorgane [Media of record and target group media]. In J. Wilke (Ed), Mediengeschichte der Bundesrepublik Deutschland [Media history of the Federal Republic of Germany]. (pp. 302-329). Köln, Weimar, and Wien: Böhlau.

Wilke, J., \& Reinemann, C. (2001). Do the candidates matter? Long-term trends of campaign coverage: A study of the German press since 1949. European Journal of Communication, 16(3), 291-314.

\section{About the Author}

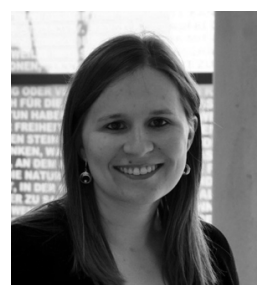

Miriam Steiner is a PhD Candidate at the Department of Communication at the Johannes Gutenberg University Mainz, Germany. Her research interests focus on media performance, particularly on news softening and media diversity. Her main issue in this respect is the media performance of journalistic content distributed on social media and through other information intermediaries such as search engines. Her research also sheds light on new forms of news consumption in the current media environment (e.g., incidental exposure on social media). 